\title{
Cloning and Characterization of a cDNA Encoding Sucrose Synthase Associated with Flower Opening through Early Senescence in Carnation (Dianthus caryophyllus L.)
}

\author{
Shigeto Morita ${ }^{1,2}$, Yuka Torii ${ }^{1}$, Taro Harada ${ }^{1 * *}$, Masaya Kawarada ${ }^{1}$, Reiko Onodera*** \\ and Shigeru Satoh ${ }^{1,2 *}$
}

${ }^{1}$ Graduate School of Life and Environmental Sciences, Kyoto Prefectural University, Kyoto 606-8522, Japan

${ }^{2}$ Kyoto Prefectural Institute of Agricultural Biotechnology, Seika-cho, Kyoto 619-0244, Japan

\begin{abstract}
Flower opening in carnations (Dianthus caryophyllus L.) is the result of the enlargement of petal cells, which requires sugar metabolism. A cDNA encoding sucrose synthase (DcSUS1) was isolated from carnation petals as a candidate gene acting in the initial step of sugar metabolism in petal cells. DcSUS1 transcripts were detected abundantly in floral tissues of flowering carnation plants; the transcripts accumulated most in the petals and style followed by the ovary, whereas only small accumulation were found in stems, leaves, and calyces. Moreover, nearly constant accumulation of DcSUS1 transcripts was found in the petals during flower opening, fully open, and early senescence periods, whereas decreasing accumulation was detected in petals when senescence progressed. These findings suggested the involvement of DcSUS1 expression in petal cell growth during the opening of carnation flowers.
\end{abstract}

Key Words: carnation, Dianthus caryophyllus, flower opening, petal cell growth, sucrose synthase.

\section{Introduction}

The vase life of cut ornamental flowers is the period from flower opening to senescence. To prolong this period, many investigators have studied the mechanism of flower opening (Harada et al., 2010; van Doorn and van Meeteren, 2003; Yamada et al., 2009a, b), and senescence (Hoeberichts et al., 2007; Hunter et al., 2004; Satoh, 2011; Shimizu-Yumoto and Ichimura, 2010; van Doorn and Woltering, 2008). We have been studying the molecular mechanism of flower opening using cut carnation flowers as a model ornamental.

Flower opening involves elongation, expansion, and outward bending of petals, which result from the enlargement of petal cells (Evans and Reid, 1988; Kenis et al., 1985; Koning, 1984). Sugar accumulation in petal

Received; August 24, 2010. Accepted; December 1, 2011.

This study was supported financially by a Grant-in-Aid (19380024 to S.S.) for Scientific Research from the Japan Society for the Promotion of Science.

* Corresponding author (E-mail: ssatoh@kpu.ac.jp)

** Present address: Horticultural Institute, Ibaraki Agricultural Center, Kasama 319-0292, Japan.

*** Present address: Yamagata Integrated Agricultural Research Center, Sagae 991-0043, Japan. cells reduces the petal water potential, and promotes water influx into the petal cells, resulting in cell enlargement (Evans and Reid, 1988; Ho and Nichols, 1977; Ichimura et al., 2003).

Sugar accumulation in petal cells is caused by a combination of sugar uptake by the cells and degradation of various polysaccharides stored in young petals in buds (van Doorn and van Meeteren, 2003). In general, sucrose is one of the prevailing sugars involved in these processes, and is metabolized by invertase and sucrose synthase (Harada et al., 2005). Invertase cleaves sucrose into glucose and fructose, and sucrose synthase converts sucrose into UDP-glucose and fructose by its reverse reaction (Giegenberger and Stitt, 1993), therefore, these enzymes probably accompany flower opening. Yamada et al. (2007) analyzed sucrose metabolism during petal growth of cut roses and suggested the involvement of invertase activities in that process. On the other hand, sucrose synthase was reported to be involved in sucrose metabolism in other plant cell growth, such as that responsible for enhanced elongation of pondweed turions (Harada et al., 2005).

To gain more insight into the sugar metabolism responsible for flower opening in carnations, we tried to clone cDNAs encoding candidate enzymes from 
carnation flowers. In the present study, we cloned and characterized the cDNA of sucrose synthase (DcSUS1) from carnation (Dianthus caryophyllus L.), and examined gene expression during the growth and development of the petals. We also searched for possible inhibitors of sucrose synthase, which are expected to be safe for humans, with easy practical use.

\section{Materials and Methods}

Plant materials and sample preparation

Cut flowers of carnation (Dianthus caryophyllus L. 'Light Pink Barbara') belonging to the spray category of carnation flowers were harvested when the first flower out of five to six flower buds was nearly open at the nursery of a commercial grower in Miyagi prefecture. The flowers were transported dry to the laboratory at Kyoto Prefectural Institute of Agricultural Biotechnology in Kyoto prefecture on the day after harvest. They were placed in plastic containers with their cut end in water under continuous light from white fluorescent lamps $\left(14 \mu \mathrm{mol} \cdot \mathrm{m}^{-2} \cdot \mathrm{s}^{-1} \mathrm{PPFD}\right)$ at $23^{\circ} \mathrm{C}$. The floweropening process was separated into 6 stages according to Harada et al. (2010): stage 1, petals just emerged from buds; stage 2 , petals elongated vertically; stage 3 , petal

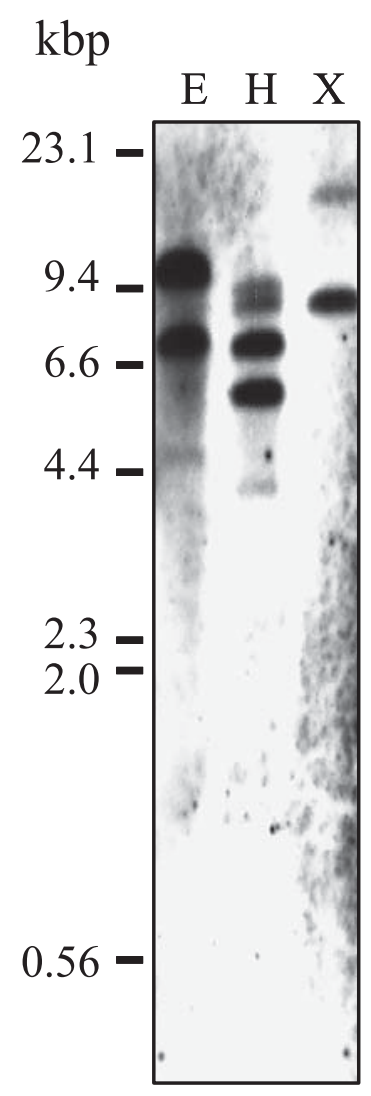

Fig. 1. Southern blot analysis of DcSUS1 gene. Genomic DNA samples were obtained from petals of 'Light Pink Barbara' carnation. Each lane contained $10 \mu \mathrm{g}$ genomic DNA digested with EcoR V (E), Hind III (H), and Xba I (X). The bolts were hybridized with the DIG-labeled DNA probe and detected with a CSPD-Star kit (Roche Diagnostics). clusters expanded; stage 4, outer petals start to reflex (bend outwards); stage 5, outer petals have reflexed; stage 6 , fully open flower with outer petals at right angles to the stem. In addition, the flower senescence process was separated into 4 stages: senescence stage 1, the last phase of fully opened flowers; senescence stage 2 , petal in-rolling and wilting started; senescence stage 3 , petal wilting culminated; senescence stage 4 , wilted petals markedly shrunk. The profiles of flower opening and senescence are shown in Figure 2.

Ten outermost petals were detached from 5 flowers at the respective stages, mixed to make one sample, and stored at $-80^{\circ} \mathrm{C}$ for extraction of RNA. Other tissues, leaves, stem, calyx, ovary, and style were detached from plants with fully opened flowers and stored as above. In carnation flowers, the stigma is along the surface of the style (rather than a distinct structure as in other flowers); therefore, the term 'style' was used to describe the style plus stigma in the following. A series of samples collected at each stage during flower opening and senescence was prepared and used for real-time PCR analysis.

\section{Measurement of ethylene production}

To determine ethylene evolution from flowers undergoing senescence, flowers were cut leaving $10 \mathrm{~mm}$ of stem and enclosed in a $240-\mathrm{mL}$ glass vessel for $1 \mathrm{~h}$. A 1-mL gas sample was then taken from the vessel and used for measurement of ethylene concentration with a gas chromatograph (GC-8A, Shimadzu, Kyoto, Japan), equipped with an alumina column (operating temperature, $80^{\circ} \mathrm{C}$ ) and a flame ionization detector.

\section{RNA extraction}

Total RNA was isolated by the cetyltrimetylammonium bromide (CTAB) method from petal tissues (Chang et al., 1993; Murry and Thompson, 1980). and precipitated with $\mathrm{LiCl}$ (Nakamura et al., 1991), or by the phenol-chloroform method, as described in Harada et al. (2005). RNA was also extracted by the phenolchloroform method from other tissues. Briefly, in the phenol-chloroform method, a sample of about $1 \mathrm{~g}$ frozen petals, or other tissues, was pulverized in liquid $\mathrm{N}_{2}$ with a mortar and pestle, and extracted with $5 \mathrm{~mL}$ extraction buffer $[1 \%$ SDS, $50 \mathrm{mM}$ Tris- $\mathrm{HCl}$ (pH 7.5), $50 \mathrm{mM}$ EDTA] plus an equal volume of water-saturated phenol. Total RNA was recovered in the supernatant after centrifugation, purified by treatment with phenolchloroform solution $(1: 1 \mathrm{v} / \mathrm{v})$ followed by chloroform, and finally precipitated with isopropanol at $-20^{\circ} \mathrm{C}$.

\section{PCR cloning of cDNA for sucrose synthase}

To obtain full-length composite cDNA for sucrose synthase, we obtained three partial-length cDNAs by ordinary RT-PCR, 3'-rapid amplification of cDNA end (3'-RACE) (Frohman et al., 1988) and 5'-RACE techniques, and then the cDNAs were combined to make 
A

Flower opening stage

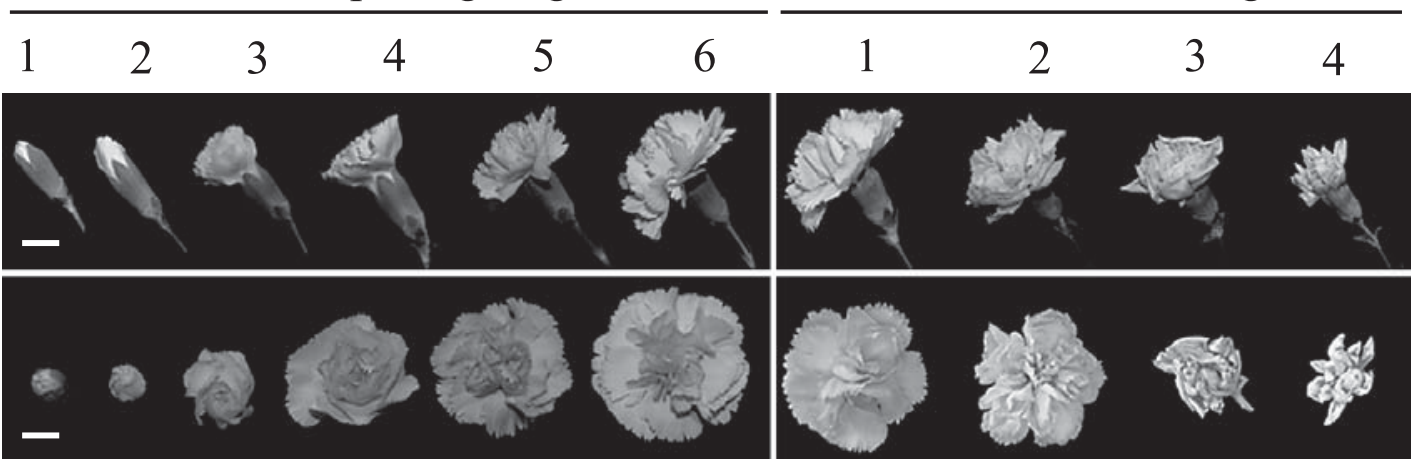

B

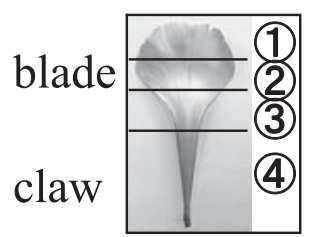

C

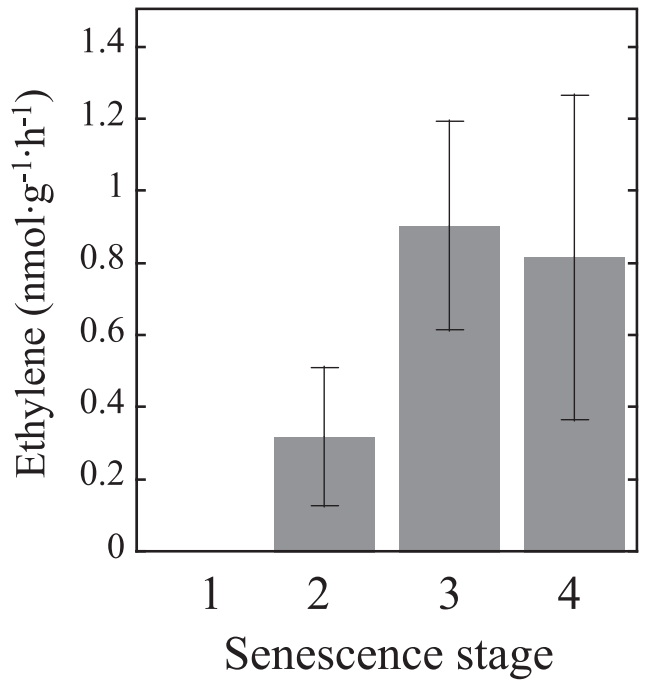

Fig. 2. Profiles of flower opening and senescence in 'Light Pink Barbara' carnation (A), separation of the petal into four parts (B), and ethylene production during senescence (C). The petal was separated into four parts as shown in Figure 1 of Harada et al. (2010) and used for DcSUS1 expression analysis in Figure 3C. More than 14 flowers at each senescence stage were used for measurement of ethylene production, and date are shown as the means $\pm \mathrm{SE}$.

a composite cDNA. Briefly, a partial length cDNA (687 bp) was amplified by RT-PCR with total RNA obtained from opening carnation petals (stage 5) and the forward (SUS1F, 5'-CCY GAY ACY GGW GGB CAG GTT GTY TAC-3') and reverse (SUS1R, 5'-CCA GGR GAS ACR ATG TTG AAC TTN GG-3') degenerate primers derived from sequences of sucrose synthase cDNAs reported in public databases. RT-PCR was performed according to the standard procedure with necessary optimization. The PCR products were cloned into pGEM-T Easy Vector (Promega, Madison, USA) for sequencing, and a nucleotide sequence was obtained. Using the nucleotide sequences, sequence-specific primers were designed. Then, a 3'-downstream cDNA of $1137 \mathrm{bp}$ was obtained by 3'-RACE with the forward SUSRACE1 primer (5'-CTT CTT GGG CTC TAC CGA GTG GTT C-3') and the reverse RT1 primer (Invitrogen, Carlsbad, USA; 5'-AAC TGG AAG AAT TCG CGG CCG GAG GAA-3'). Finally, a 5'-upstream cDNA of $1106 \mathrm{bp}$ was obtained by $5^{\prime}$-RACE with the forward GeneRacer 5'primer (Invitrogen; 5'-CGA CUG GAG
CAC GAG GAC ACU GA-3') and the reverse DcSUS1RACE primer (5'-CTG CGT CAG GGA GCA GAC GAG TTA CAA-3'). The three partial cDNAs were reconstituted to make the composite cDNA (DcSUS1) of $2790 \mathrm{bp}$, including polyA sequence. Then, to confirm complete nucleotide sequences, a full-length cDNA $(2690 \mathrm{bp}$ ) was amplified from total RNA obtained from opening carnation petals as templates with primers derived from both ends of the composite cDNA (forward DcSUS1-F1 primer, 5'-ACA CTC CTC TAC TCT TCC CT-3'; reverse DcSUS1-R1 primer, 5'-ATC AAA CAC AAA TGC CTC AAA GAG C-3'). The nucleotide sequence of the cDNA was obtained, and the complete sequence was confirmed to be identical with the composite sequence.

\section{Southern blot analysis}

Genomic DNA was isolated from 'Light Pink Barbara' carnation petals by the CTAB method (Hasebe and Iwatsuki, 1990). Ten micrograms of genomic DNA were digested with EcoR V, Hind III, Xba I and separated on 
a $0.8 \%$ agarose gel and transferred to a nylon membrane (Hybond $\mathrm{N}^{+}$, Amersham Pharmacia Biotech, Piscataway, USA). A DcSUS1 cDNA fragment, $725 \mathrm{bp}$, was amplified by PCR with the forward SUS2F primer (5'GTG GAT CTC TGC GCA GAT GAA CCG-3') and the reverse RT1 primer, and used as the probe for gel blot analysis. The DNA probe was labeled with DIG using the DIG DNA labeling kit (Roche Diagnostics, Mannheim, Germany). After hybridization with the blot, the hybridization signals were detected by chemiluminescence using CSPD-Star (Roche Diagnostics) as a substrate, and recorded on an X-ray film (RX-U, Fuji Photo Film, Tokyo, Japan).

\section{Real-time PCR}

Real-time RT-PCR for the quantification of transcripts for DcSUS1 was conducted using the LightCycler FastStart DNA Master SYBR Green I Kit and the LightCycler Instrument (Roche Diagnostics). cDNA was synthesized using ReverTra Ace (TOYOBO, Osaka, Japan) according to the manufacturer's instructions. The primer sets for real-time PCR were the forward SUS3F and the reverse SUS3R for carnation DcSUS1, and the forward DcACT1P51F (5'-CGT CAC CAA CTG GGA TGA CA-3') and the reverse DcACT1P229R (5'-GAG AGA ACG GCC TCC ATG GC-3') primers for carnation actin [DcACT1, accession number (acc. no.) AY0073415] mRNA (Waki et al., 2001). The sizes of amplificates were $196 \mathrm{bp}$ and $198 \mathrm{bp}$ for DcSUS1 and DCACT1, respectively. PCR conditions were initial heating for $10 \mathrm{~min}$ at $95^{\circ} \mathrm{C}$ followed by 40 cycles of $5 \mathrm{~s}$ at $95^{\circ} \mathrm{C}, 5 \mathrm{~s}$ at $53^{\circ} \mathrm{C}, 8 \mathrm{~s}$ at $72^{\circ} \mathrm{C}$, in which the extension time was adopted according to the length of amplificates (1 s per 25 mer). The absolute transcript level was calculated using a dilution series of a target sequence on LightCycler Software Ver. 3.5 (Roche Diagnostics).
DcACT1 had an almost constant transcript level throughout the flower-opening stages and tissues, and was used to normalize the transcript level (Fig. 3). On the other hand, the amount of DcACT1 transcripts was found to decrease markedly in the later stages of petal senescence, suggesting that the use of $D c A C T 1$ transcript as a normalizing standard would result in an overestimation of DcSUS1 transcript (Jones, 2004); therefore, in the case of senescing carnation petals, we showed the transcript levels of DcSUS1 on the basis of total RNA (Fig.4). Three RNA preparations per stage were independently used for analyses, and data are shown as the mean $\pm \mathrm{SE}$ of the three preparations for each stage.

\section{Effects of sucrose analogs on flowering}

Flowers of 'Light Pink Barbara' carnation at opening stage 2 with $10 \mathrm{~cm}$ stems were put in $50-\mathrm{mL}$ plastic tubes ( 3 flowers per tube), dipping their stem ends in 20-mL test solution containing sucrose and its analogs at $0.1 \mathrm{M}$. The sucrose analogs used were trehalose, palatinose, and sucralose. The control was distilled water. The test solution contained isothiazolinone derivatives (0.01\% Legend $\mathrm{MK}^{\circledR}$, Cresta Japan, Chiba, Japan) as a bactericide. Experiments were repeated twice. Four replicated plastic vessels were used per treatment for experiment 1 , but three replicates for experiment 2 . The flowers were left at $21^{\circ} \mathrm{C}$ under continuous light from white fluorescent lamps $\left(14 \mu \mathrm{mol} \cdot \mathrm{m}^{-2} \cdot \mathrm{s}^{-1} \mathrm{PPFD}\right)$. Flower opening was observed daily, and days from floweropening stage 2 until stage 4 were determined for each vessel by averaging the values obtained with 3 flowers. Data are shown as the mean $\pm \mathrm{SE}$ of four or three replicated vessels. Data were analyzed by Dunnett's multiple range test.

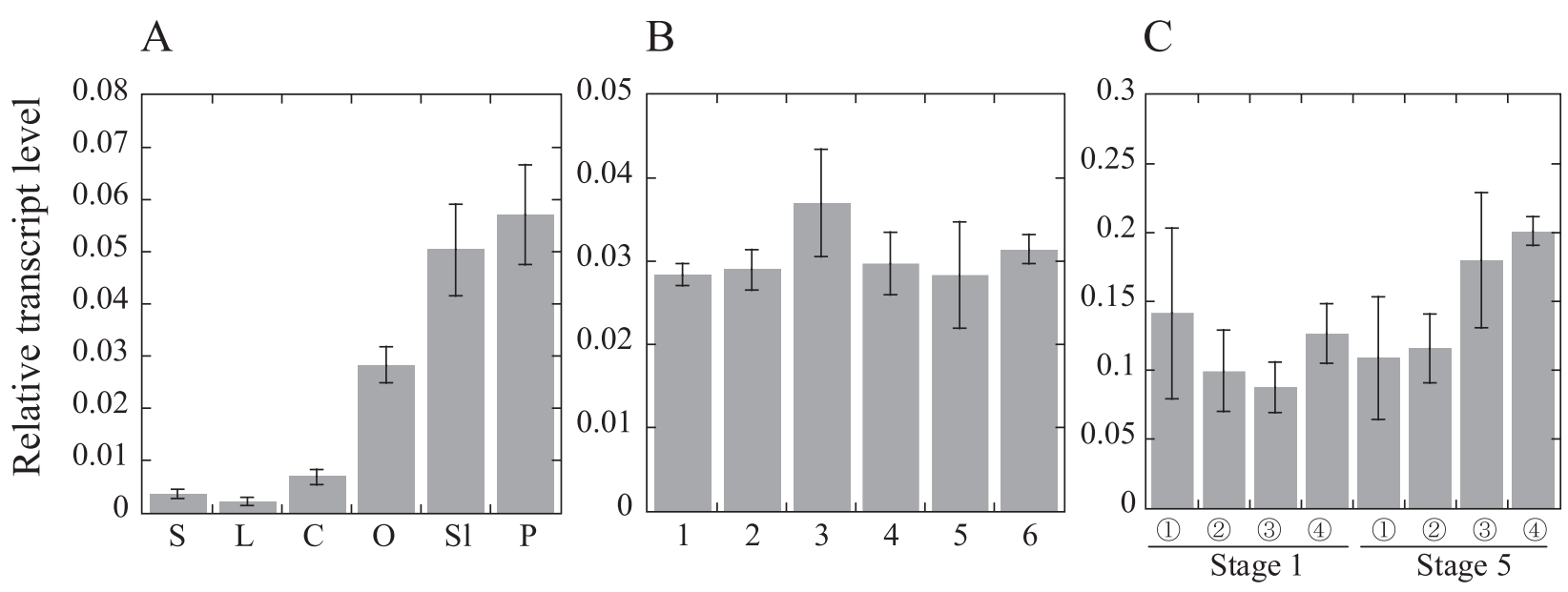

Fig. 3. Comparison of transcript levels of the DcSUS1 gene among different tissues (A), and their changes in whole petals at each stage (B) and different parts of petals (C) during flower opening. Transcript levels for DcSUS1 and DcACT1 were determined by real-time RT-PCR, and DcSUS1 transcript level relative to that of DcACT1 are shown. Data are the means $\pm \mathrm{SE}$ of three separate samples. Abbreviations in the abscissa of the panel A: S, stem; L, leaf; C, calyx; O, ovary; Sl, style (actually style plus stigma); P, petal. Photographs of flowers at each stage during flower opening for (B) and petal portions for (C) are shown in Figure 2A and 2B, respectively. 


\section{Results and Discussion}

\section{Cloning and characterization of DcSUS1}

We isolated a 2769-bp long cDNA fragment encoding a putative sucrose synthase from 'Light Pink Barbara' carnation using a combination of RT-PCR, 3'-RACE and 5 '-RACE techniques. The cDNA had an entire open reading frame of $2406 \mathrm{bp}$, and 91-bp long 5'- and 272bp long 3'-marginal sequences. The deduced protein consisted of 801 amino acid residues and had a molecular mass of $91 \mathrm{kDa}$. The protein had an amino acid sequence of DTGGQVVY at amino acid 299-306, which is conserved among sucrose synthases from different plants. These findings combined with those by homology analysis shown below indicated that the cDNA encoded a putative sucrose synthase. The cDNA was designated DcSUS1 (ㅁianthus ㄸaryophyllus sucrose synthase 1 ) and deposited in DDBJ (acc. no. AB543810).

DcSUS1 had an amino acid sequence similar to other sucrose synthases; similarity revealed by BLAST analysis was $90.1 \%$ for chenopodium CSS1 (Chenopodium rubrum, acc. no. X82504) (Godt et al., 1995), 89.9\% for beet SBSS2 (Beta vulgaris, acc. no. AY457173) (Haagenson et al., 2006), 81.9\% for mandarin orange CitSUS1 (Citrus unshiu, acc. no. AB022092) (Komatsu et al., 2002), $82.5 \%$ for watermelon WSUS (Citrullus lanatus, acc. no. AB018561), and $82.5 \%$ for eucalyptus SuSy3 (Eucalyptus grandis, acc. no. DQ22794). The homology was markedly high among carnation DcSUS1, chenopodium CSS1, and beet SBSS2. This finding suggests a close relationship among carnation, chenopodium, and beet in terms of sucrose synthase proteins. This agrees with the fact that carnation (Dianthus caryophyllus), chenopodium (Chenopodium rubrum), and sugar beet (Beta vulgaris) belong to the order Caryophyllales.

Southern blot analysis of genomic DNA obtained from 'Light Pink Barbara' carnation showed two or more bands after digestion with three restriction enzymes (Fig. 1). These findings suggested that there are at least two DcSUS1 copies in 'Light Pink Barbara' carnation.

\section{Flower opening, senescence, and ethylene production in 'Light Pink Barbara' carnation}

Figure 2A shows the profile of flower opening and senescence. The flower-opening process was separated into six stages according to Harada et al. (2010), whereas the flower senescence process was separated into four stages. Duration from flower-opening stage 6 to senescence stage 1 could be regarded as the fully open stage.

Ethylene production from whole flowers was not detected at senescence stage 1, but became detectable at senescence stage 2 and then increased at senescence stages 3 and 4 (Fig. 2C). The maximum rate of ethylene production $\left(0.91 \pm 0.29 \mathrm{nmol} \cdot \mathrm{g}^{-1} \cdot \mathrm{h}^{-1}\right)$ at senescence stage 3 was comparable to that observed previously, such as $1.42 \pm 0.33 \mathrm{nmol} \cdot \mathrm{g}^{-1} \cdot \mathrm{h}^{-1}$ (Otsu et al., 2007).

\section{Expression analysis of DcSUS1}

Figure 3 shows the relative transcript levels of DcSUSI in different tissues of carnation plants with opening flowers (A), in whole petals at each opening stage (B), and in different parts of petals at opening stages 1 and 5 (C). Large amounts of DcSUS1 transcript accumulated in the petals and style (actually style plus stigma), followed by the ovary. In contrast, there was little accumulation of DcSUS1 transcript in the stems, leaves, and calyces. These findings suggested that DcSUS1 is expressed largely in floral tissues but scarcely, if any, in vegetative green tissues. As shown in Figure 3B, in whole petals, DcSUS1 transcript was already accumulated at flower-opening stage 1 (buds), and its level was maintained nearly constant until flower-opening stage 6 (fully open flower). Figure 3C shows that DcSUS1 transcripts were present in four longitudinally successive parts of petals (Fig. 2B) at flower-opening stages 1 and 5. There was little difference in the DcSUS1 transcript level among petal parts at both flower-opening stages.

On the other hand, the DcSUS1 transcript was detected at flower senescence stages 1 and 2, and markedly decreased at senescence stages 3 and 4 (Fig. 4). The presence of the transcript in petals in senescence stages 1 and 2 suggested that DcSUSI was expressed in the petals of carnation flowers at fully open and early senescence stages.

The present findings are slightly different from those reported by Panavas et al. (1999), who showed that the mRNA level of the sucrose synthase gene increased during the growth and development of tepals of daylily flowers. We conclude that the DcSUS1 gene expression

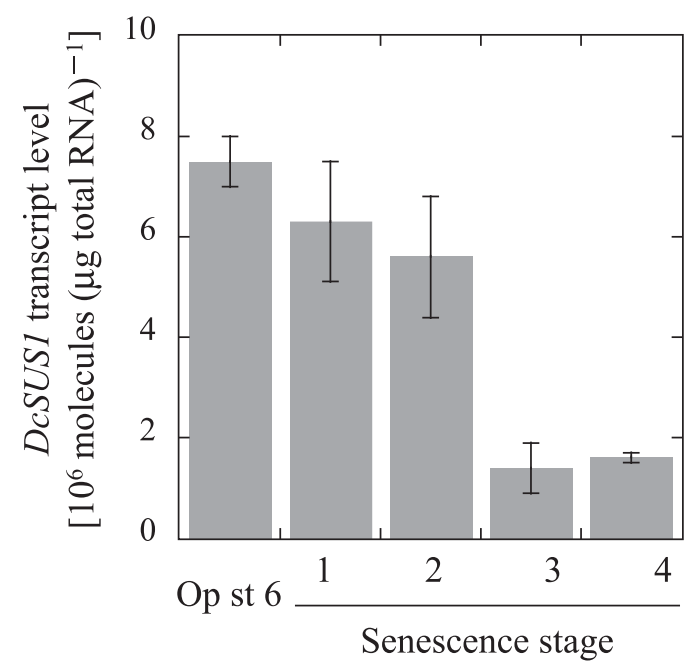

Fig. 4. Changes in transcript levels of DcSUS1 gene in whole petals of carnation flowers undergoing senescence. Transcript levels are determined by real-time RT-PCR on the basis of given amounts of total RNA, since amounts of DcACT1 mRNA decreased markedly at later senescing stages. Data for openingstage 6 were the data used in Figure 3B, but before normalizing with the amount of DcACT1 mRNA. Photographs of flowers at each senescing stage are shown in Figure 2A. Data are the means \pm SE of three separate samples. Op st 6 stands for opening-stage 6 . 
at high level is associated with the progress of petal development in carnation flower opening and to maintain them fully open.

\section{Trial search for possible inhibitors of sucrose synthase in carnation petals}

Based on the present findings we considered that if the action of DcSUS1 could be prevented, the progress of flower opening would be retarded, resulting in lengthening the flower display time. This may be achieved by inhibition of DcSUS1 protein synthesis itself by application of cycloheximide (a protein synthesis inhibitor) and perhaps actinomycin D (an RNA synthesis inhibitor). In the past, many reports showed that cycloheximide prevented the senescence of carnation flowers or their isolated petals, although its mechanism of action was explained differently (Halaba and Rudnicki, 1985; Taverner et al., 2000; Wulster et al., 1981, 1982a, b). To our best knowledge, there have been no reports in which the effects of these inhibitors on carnation flower opening were tested. On the other hand, cycloheximide and actinomycin D are very toxic to humans and livestock, which allowed them to be used only for experimental tools and never as preservatives used practically in the flower industry. This situation will not change in the future.

Therefore, we took another approach to find possible inhibitors of sucrose synthase with the expectation that they, if active, would retard the progress of flower opening. We searched for possible inhibitors in sucrose analogs, keeping the following expectations in mind: (1) the sucrose analogs would compete with sucrose at the active site of the enzyme, resulting in inhibition of the enzyme's action, and (2) they would be safe for humans and livestock when used practically in the flower industry since they are already used as food additives or, if not, they are expected to be metabolized easily by humans and livestock.

We tested the effects of trehalose, palatinose, and sucralose, as well as sucrose itself (Table 1). The days from flower-opening stage 2 to stage 4 varied from 3.7 days to 4.9 days in experiment 1 , and from 4.3 days to 6.3 days in experiment 2 . There was no significance in the duration of flower opening (days from stage 2 to

Table 1. Effects of sucrose and its analogs applied exogenously at $0.1 \mathrm{M}$ on the progress of flowering in cut carnation flowers.

\begin{tabular}{lcc}
\hline \hline \multirow{2}{*}{ Treatment } & \multicolumn{2}{c}{ Days from stage 2 to stage 4 } \\
\cline { 2 - 3 } & Experiment 1 & Experiment 2 \\
\hline Control $\left(\mathrm{H}_{2} \mathrm{O}\right)$ & $4.0 \pm 0.3$ & $4.8 \pm 0.3$ \\
Sucrose & $3.7 \pm 0.3$ & $4.3 \pm 0.2$ \\
Trehalose & $4.7 \pm 0.2$ & $5.9 \pm 0.4$ \\
Palatinose & $3.6 \pm 0.5$ & $5.2 \pm 0.1$ \\
Sucralose $^{\mathrm{z}}$ & $4.7 \pm 0.6$ & $6.3^{*} \pm 0.9$ \\
\hline
\end{tabular}

${ }^{\mathrm{z}}$ Severe injury was caused to calyces.

* Significantly different by Dunnett's multiple range test $(P<0.05)$. stage 4) between the control flowers and flowers treated with sucrose and its analogs, except those treated with sucralose at $0.1 \mathrm{M}$. However, severe injury occurred in the calyces of flowers treated with $0.1 \mathrm{M}$ sucralose for 2 days, indicating that the delay of flower opening might have been caused by side negative effects of the chemicals other than the inhibition of sucrose synthase. In addition to the above experiment, we preliminarily tested sucrose analogs at lower or higher concentrations, i.e., isomaltose at $29.2 \mathrm{mM}$, trehalose at 29.2, 87.6, and $292 \mathrm{mM}$, palatinose 29.2, 87.6, and $292 \mathrm{mM}$, and sucralose at $0.3,1$, and $10 \mathrm{mM}$; however, these chemicals at given concentrations did not delay the rate of flower opening (data not shown). Although the sucrose analogs used in the present experiment did not affect the flower opening of carnations, we believe that it is worth conducting this trial with different kinds of flowers and chemicals to pursue sucrose analogs which inhibit sucrose synthase activity.

\section{Literature Cited}

Chang, S., J. Puryer and J. Cairney. 1993. A simple and efficient method for isolation of RNA from pine trees. Plant Mol. Biol. Rep. 11: 113-116.

Evans, R. Y. and M. S. Reid. 1988. Changes in carbohydrates and osmotic potential during rhythmic expansion of rose petals. J. Amer. Soc. Hort. Sci. 113: 884-888.

Frohman, M. A., M. K. Dush and G. R. Martin. 1988. Rapid production of full-length cDNAs from rare transcripts: amplification using a single gene-specific oligonucleotide primer. Proc. Natl. Acad. Sci. USA 85: 8998-9002.

Geigenberger, P. and M. Stitt. 1993. Sucrose synthase catalyses a readily reversible reaction in vivo in developing potato tubers and other plant tissues. Planta 189: 329-339.

Godt, D. E., A. Riegel and T. Roitsch. 1995. Regulation of sucrose synthase expression in Chenopodium rubrum: characterization of sugar induced expression in photoautotrophic suspension cultures and sink specific expression in plants. J. Plant Physiol. 146: 231-238.

Haagenson, D. M., K. L. Klotz and J. M. McGrath. 2006. Sugarbeet sucrose synthase gene differ in organ-specific and developmental expression. J. Plant Physiol. 163: 102-106.

Halaba, J. and R. M. Rudnicki. 1985. Invertase inhibitor-control of sucrose transportation from petals to other flower parts. Acta Hort. 167: 159.

Harada, T., S. Satoh, T. Yoshioka and K. Ishizawa. 2005. Expression of sucrose synthase genes involved in enhanced elongation of pondweed (Potamogeton distinctus) turions under anoxia. Ann. Bot. 96: 683-692.

Harada, T., Y. Torii, S. Morita, T. Masumura and S. Satoh. 2010 Differential expression of genes identified by suppression subtractive hybridization in petals of opening carnation flowers. J. Exp. Bot. 61: 2345-2354.

Hasebe, M. and K. Iwatsuki. 1990. Adiantum capillus-veneris chloroplast DNA clone bank: as useful heterologous probes in the systematics of the leptosporangiate ferns. Amer. Fern J. $80: 20-25$.

Ho, L. C. and R. Nichols. 1977. Translocation of ${ }^{14} \mathrm{C}$-sucrose in relation to changes in carbohydrate content in rose corollas cut at different stages of development. Ann. Bot. 41:227-242.

Hoeberichts, F. A., W. G. van Doorn, O. Vorst, R. D. Hall and M. F. van Wardragen. 2007. Sucrose prevents up-regulation 
of senescence-associated genes in carnation petals. J. Exp. Bot. 58: 2873-2885.

Hunter, D. A., N. E. Lange and S. M. Reid. 2004. Physiology of flower senescence. p. 307-318. In: L. D. Nooden (ed.). Plant cell death processes. Elsevier Science, San Diego.

Ichimura, K., Y. Kawabata, M. Kishimoto, R. Goto and K. Yamada. 2003. Shortage of soluble carbohydrates is largely responsible for short vase life of cut 'Sonia' rose flowers. J. Japan. Soc. Hort. Sci. 72: 292-298.

Jones, M. 2004. Changes in gene expression during senescence. p. 51-72. In: L. D. Nooden (ed.). Plant cell death processes, Elsevier Science, San Diego.

Kenis, J. D., S. T. Silvente and V. S. Trippi. 1985. Nitrogen metabolite and senescence-associated change during growth of carnation flowers. Physiol. Plant. 65: 455-459.

Komatsu, A., T. Moriguchi, K. Koyama, M. Omura and T. Akihama. 2002. Analysis of sucrose synthase genes in citrus suggests different roles and phylogenetic relationships. J. Exp. Bot. 53: 61-71.

Koning, R. E. 1984. The role of plant hormones in the growth of the corolla of Gaillardia grandiflora (Asteraceae) ray flowers. Amer. J. Bot. 71: 1-8.

Murry, M. G. and W. F. Thompson. 1980. Rapid isolation of high molecular weight plant DNA. Nucl. Acids Res. 8: 4321-4325.

Nakamura, K., M. Ohto, N. Yoshida and K. Nakamura. 1991. Sucrose-induced accumulation of $\alpha$-amylase occurs concomitant with the accumulation of starch and sporamin in leafpetiole cuttings of sweet potato. Plant Physiol. 96: 902-909.

Otsu, S., S. Satoh and Y. Kosugi. 2007. Expression of senescence related genes in carnation petals undergoing wilting and fading. Acta Hort. 763: 283-287.

Panavas, T., A. Pikula, P. D. Reid, B. Rubinstein and E. L. Walker. 1999. Identification of senescence-associated genes from daylily petals. Plant Mol. Biol. 40: 237-248.

Satoh, S. 2011. Ethylene production and petal wilting during senescence of cut carnation (Dianthus caryophyllus) flowers and prolonging their vase life by genetic transformation. J.
Japan. Soc. Hort. Sci. 80: 127-135.

Shimizu-Yumoto, H. and K. Ichimura. 2010. Postharvest physiology and technology of cut Eustoma flowers. J. Japan. Soc. Hort. Sci. 79: 227-238.

Taverner, E. A., D. S. Letham, J. Wang and E. Crornish. 2000. Inhibition of carnation petal inrolling by growth retardants and cytokinins. Aust. J. Plant Physiol. 27: 357-362.

van Doorn, W. G. and U. van Meeteren. 2003. Flower opening and closure: a review. J. Exp. Bot. 54: 1801-1812.

van Doorn, W. G. and E. J. Woltering. 2008. Physiology and molecular biology of petal senescence. J. Exp. Bot. 59: 453480 .

Waki, K., K. Shibuya, T. Yoshioka, T. Hashiba and S. Satoh. 2001. Cloning of a cDNA encoding EIN3-like protein (DC-EIL1) and decrease in its mRNA level during senescence in carnation flower tissues. J. Exp. Bot. 52: 377-379.

Wulster, G., J. Sacalis and H. Janes. 1981. Effects of inhibitors of protein synthesis on senescence in isolated carnation petals after exposure to ethylene. HortSicence 16: 404.

Wulster, G., J. Sacalis and H. Janes. 1982a. The effect of inhibitors of protein synthesis on ethylene induced senescence in isolated carnation petals. J. Amer. Soc. Hort. Sci. 107: 112115.

Wulster, G., J. Sacalis and H. Janes. 1982b. Senescence in isolated carnation petals. Effects of indoleacetic acid and inhibitors of protein synthesis. Plant Physiol. 70: 1039-1043.

Yamada, K., M. Ito, T. Oyama, M. Nakada, M. Maesaka and S. Yamaki. 2007. Analysis of sucrose metabolism during petal growth of cut roses. Postharvest Biol. Technol. 43: 174-177.

Yamada, K., R. Norikoshi, K. Suzuki, T. Nishijima, H. Imanishi and K. Ichimura. 2009a. Cell division and expansion growth during rose petal development. J. Japan. Soc. Hort. Sci. 78: 356-362.

Yamada, K., R. Takahashi, C. Fujitani, K. Mishima, M. Yoshida, D. C. Joyce and Y. Yamaki. 2009b. Cell wall extensibility and effect of cell-wall-loosening proteins during rose flower opening. J. Japan. Soc. Hort. Sci. 78: 242-251. 